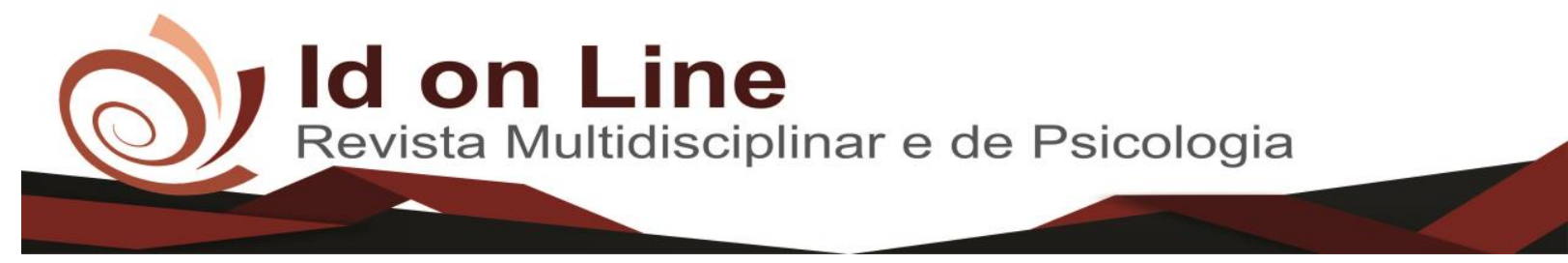

Artigo

\title{
Marketing Estratégico como Fator Competitivo nas Organizações de Pequeno Porte
}

Samuel Pinheiro dos Santos ${ }^{1}$; Márcia Maria Leite Lima²

\begin{abstract}
Resumo: O marketing estratégico é uma ferramenta que trabalha as questões mercadológicas de gestão, envolvendo as necessidades do cliente no desenvolvimento de atividades e decisões organizacionais para o atendimento das mesmas. Portanto objetivo deste estudo é analisar os fatores que levam os discentes optarem por produtos alimentícios comercializados por ambulantes próximos as IES na cidade de Juazeiro do Norte-CE. Para o alcance dos resultados este estudo tem uma abordagem de métodos quantitativos, exploratório e descritiva. Com os resultados obtidos identificou-se como fatores influenciadores em relação à decisão de compra dos participantes a qualidade no atendimento, a oferta de produtos variados pelos ambulantes, comodidade no oferecimento dos seus lanches, os preços mais acessíveis, relacionamento com o cliente e a satisfação com qualidade dos produtos ofertados pelos empreendedores ambulantes alimentícios.
\end{abstract}

Palavras-chave: Marketing. Planejamento. Estratégia.

\section{Strategic Marketing as a Competitive Factor in Small Business Organizations}

\begin{abstract}
The strategic marketing is a tool that works the subject's administration marketing, involving the customer's needs in the development of activities and organizational decisions for the service of the same ones. Therefore I aim at of this study is to analyze the factors that take the students choose for nutritious products marketed for traveling close IES in the city of Juazeiro of the North-CE. For the reach of the results this study has a quantitative, exploratory and descriptive approach of methods. With the obtained results he/she identified as factors influencers in relation to the decision of the participants' purchase the quality in the service, the offer of varied products for the traveling ones, comfort in the offer of their snacks, the most accessible prices, relationship with the customer and the satisfaction with quality of the products presented by the nutritious traveling entrepreneurs.
\end{abstract}

Keywords: Marketing. Planning. Strategy.

\section{Introdução}

Com o aumento da concorrência as empresas sentem a necessidade de planejar suas ações e se adaptarem rapidamente às modificações do mercado, tornando-se cada vez mais

\footnotetext{
${ }^{1}$ Graduando o curso de Administração do Centro Universitário Doutor Leão Sampaio/Unileão.

Samuel-pinheiro2014@bol.com.br

${ }^{2}$ Professora de graduação do Centro Universitário Doutor Leão Sampaio/Unileão especialista em Gestão de Estratégia e Pessoas - marcialeite@ leaosampaio.edu.br
} 1119 Id on Line Rev. Mult. Psic. V.12, N. 42, p. 1119-1142, 2018 - ISSN 1981-1179
Edição eletrônica em http://idonline.emnuvens.com.br/id 
competitivas para garantir sua permanência no mesmo. A partir da nova ordem econômica, do processo de globalização e do desenvolvimento tecnológico, instalou-se uma nova ordem de negócios na qual o objetivo de superação do concorrente faz que as empresas se lancem em busca de novos modelos de gestão.

E por meio dessas mudanças surge a gestão de marketing que se tornou uma função desenvolvida a partir de uma visão tradicional de vendas, com ênfase em planejamento e desenvolvimento de produtos, preços, promoção e distribuição. Esse enfoque valoriza a importância da pesquisa e planejamento de marketing como um veículo para identificar e solucionar as necessidades do mercado. Neste contexto, muitas organizações de pequeno porte, não apostam na importância do marketing para o seu negócio, talvez porque a demanda ainda é baixa, ou porque o nível de concorrência é baixo, ou mesmo porque o interesse às vezes é só de manter- se no mercado e não necessariamente crescer e migrar de micro para uma grande empresa. Dentro deste contexto é importante visualizar o fluxo de influencias em que o ambiente da organização está inserido, tendo em vista se o ambiente induz a estratégia que conduz ao posicionamento de vantagem competitiva.

O presente artigo teme como problemática discutir a utilização do Planejamento de Marketing Estratégico utilizado pelos empreendedores ambulantes no segmento alimentício próximo a uma IES particular na cidade de Juazeiro do Norte - CE. Tendo como hipóteses se os alimentos vendidos pelos empreendedores ambulantes são mais baratos que os produtos oferecidos em cantinas; os empreendedores ambulantes possui um mix de produtos mais diversificado; o atendimento popular dos empreendedores ambulantes é vistos como uma vantagem competitiva pelos discentes da IES; o local apesar de não oferecer segurança ainda é mais agradável que o ambiente das cantinas.

Com base neste contexto apresentado o objetivo deste estudo é Identificar os fatores que levam os discentes de uma IES particular optarem por produtos alimentícios comercializados por empreendedores ambulantes na cidade de Juazeiro do Norte - CE. Tendo como objetivos específicos: entender partir do ponto de vista do cliente o que é um bom atendimento; avaliar se os produtos ofertados pelos ambulantes são mais atrativos que os comercializados pelas cantinas; Analisar se o ambiente pode ser um fator diferencial na escolha do cliente; Identificar se custos benefícios do produto é compatível as condições financeiras do cliente. 
Partindo dessa premissa este estudo se justifica a importância do suporte que o planejamento de marketing estratégico dá as empresas na relação produto/cliente e na sua atual relevância frente ao mercado competitivo dos dias atuais. Este estudo será disponibilizado como subsídio para a comunidade acadêmica aprimorar conhecimentos sobre o assunto, incentivando estudos sobre as novas necessidades e tendências do mercado. Além de proporcionar maior conhecimento para a formação profissional do autor.

\section{Fundamentação Teórica}

Para um melhor entendimento será presentado neste artigo abordagens teóricas sobre: Planejamento Nas Organizações; Conceitos Sobre Marketing; Planejamento De Marketing Estratégico; Comportamento Do Consumidor e Fidelização De Clientes.

\section{Planejamento nas Organizações}

Em um cenário onde a geração de negócios se sobrepõe à geração de vendas, o grande desafio da organização passa a ser a conquista e, principalmente, a manutenção e gestão de um relacionamento rentável com os clientes. Portanto é fundamental a discursão acerca dos fatores chaves da competitividade organizacional. Para isso, Aguilera (2009) ressalta a importância das técnicas utilizadas pelos gestores, entre essas técnicas o autor ressalta que o planejamento é um dos mais importantes processos de gestão. O planejamento permite disseminar por toda a corporação as principais diretrizes e estratégias da companhia, tornando-se também uma ferramenta eficiente de treinamento e desenvolvimento das pessoas (AGUILERA, 2009).

$\mathrm{Na}$ visão de Las Casas (2006) o planejamento deve ser realizado para tomada de decisões antecipadas, para isso é necessário conhecer o ambiente organizacional determinando metas e objetivos a serem alcançados. Para Hartline (2010), o planejamento vai de acordo com a complexidade da organização, quanto mais complexa for a estrutura organizacional, maior o nível de dificuldade de implantar o planejamento. No entanto, tendo em visa todo esse contexto apresentado sobre a importância do planejamento, surge a necessidade do incentivo aos gestores para a realização de planejamento dentro de suas organizações, tendo em vista as vantagens 
competitivas no ambiente organizacional. Para uma melhor compreensão Las Casas (2013) apresenta na figura 01 os três tipos de planejamento organizacional.

Figura 01: Níveis de Planejamento Organizacional.

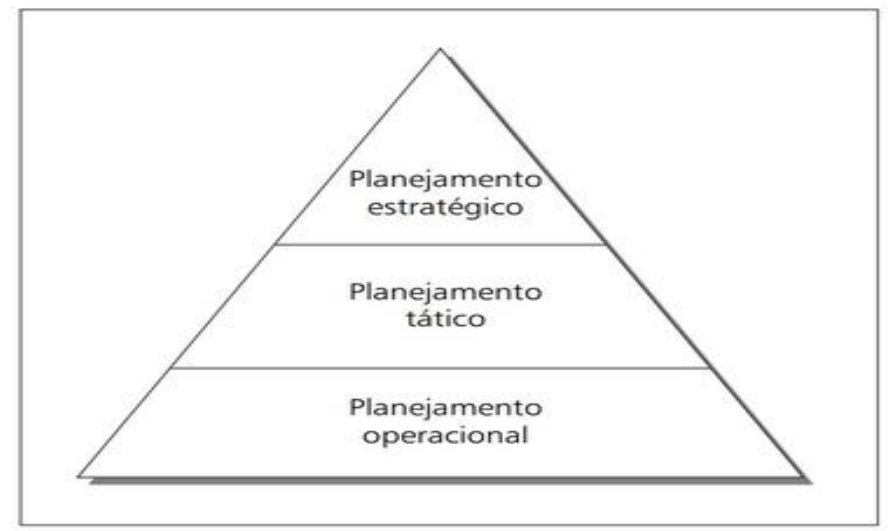

Fonte: Extraído de Las Casas (2013).

Observa-se que na figura 01, o planejamento é dividido em três níveis, sendo eles: estratégico, tático e operacional. Dessa forma o planejamento está correlacionado aos níveis de decisão e hierarquia numa pirâmide organizacional. Este mesmo autor, destaca que, o objetivo do planejamento é desenvolver processos, técnicas e atitudes administrativas para que a organização possa alcançar os seus objetivos.

De forma resumida, Las Casas (2013) define no quadro 01 os níveis de planejamento e suas respectivas funções dentro da organização.

Quadro 01: Níveis de Planejamento e suas Respectivas Funções Dentro da Organização.

\begin{tabular}{|c|l|}
\hline $\begin{array}{c}\text { Planejamento } \\
\text { Estratégico }\end{array}$ & $\begin{array}{l}\text { é o processo administrativo que proporciona sustentação metodológica para se } \\
\text { estabelecer a melhor direção a ser seguida pela empresa, visando ao otimizado grau de } \\
\text { interação com os fatores externos - não controláveis - e atuando de forma inovadora e } \\
\text { diferenciada. Esse nível é, normalmente, de responsabilidade dos níveis mais altos da } \\
\text { empresa. }\end{array}$ \\
\hline $\begin{array}{c}\text { Planejamento } \\
\text { Tático }\end{array}$ & $\begin{array}{l}\text { é a metodologia administrativa que tem por finalidade otimizar determinada área de } \\
\text { resultado e não a empresa como um todo. Portanto, trabalha com decomposições dos } \\
\text { objetivos, estratégias e políticas estabelecidos no planejamento estratégico. Esse nível é } \\
\text { desenvolvido pelos níveis organizacionais intermediários. }\end{array}$ \\
$\begin{array}{c}\text { Planejamento } \\
\text { Operacional }\end{array}$ & $\begin{array}{l}\text { é a formalização, principalmente através de documentos escritos, das metodologias de } \\
\text { desenvolvimento e implementação de resultados específicos a serem alcançados pelas } \\
\text { áreas funcionais da empresa. O operacional normalmente, elaborado pelos níveis } \\
\text { organizacionais inferiores da estruturação hierárquica. }\end{array}$ \\
\hline
\end{tabular}
Fonte: Las Casas (2013). 
Desta forma, é importante compreender que as organizações são entendidas preliminarmente como resultado produzido pelas atividades da estrutura organizacional. Partindo da premissa que, para melhorar o desempenho de uma empresa é preciso passar por duas importantes fases: processo e construção. "Processo" porque a estrutura organizacional não nasce pronta e também não há fim, ela precisa a todo momento encontrar condições de recriar e se adaptar as novas situações internas e externas do ambiente. Em relação a “Construção" esse processo se dar por meio de novas experiências, normalmente é eliminado o obsoleto (GIOVANINI, 2004).

Porém, Giovanini (2004) numa outra visão organizacional o teórico Swaim (2011) a através da visão de Drucker, afirma que uma empresa possui duas funções básicas: essas funções são o Marketing e a outra a Inovação. O referido autor enfatiza que o marketing começa pelo consumidor, sua demografia, suas realidades, suas necessidades, seus valores. Já a inovação não basta a empresa oferecer uma mercadoria ou serviço qualquer; ela precisa oferecer produtos e serviços melhores e mais econômicos.

\section{Conceituando Marketing}

$\mathrm{O}$ ato da troca existe desde o início dos tempos e o comércio é uma das mais antigas atividades humanas. A atividade da troca comercial representava uma nova e diferente forma de comportamento. Os estudiosos que iniciaram as primeiras discussões sobre marketing buscavam compreender seu impacto na sociedade. O filósofo socrático introduziu as primeiras bases para a discussão referente à integração do marketing com a sociedade. Este debate foi expandido por outros intelectuais (SIMÕES, 1980).

No entanto, até nos dias de hoje, em uma visão mais moderna, o teórico Kotler (1994) afirma que o marketing está essencialmente ligado à troca. Porém, a termologia Marketing é recente de uma prática cujas origens remontam aos primórdios da troca e comércio (MOTTA, 1983). O nascimento do marketing historicamente surge no século $\mathrm{XX}$, em formato de disciplina ofertada por cinco universidades americanas em cursos sobre o tema (CHAUVEL, 2001). De acordo com os teóricos Jones; Shaw (2002) na época em que a disciplina de Marketing surgiu, a história era parte fundamental do que os professores estudavam e

1123 Id on Line Rev. Mult. Psic. V.12, N. 42, p. 1119-1142, 2018 - ISSN 1981-1179 Edição eletrônica em http://idonline.emnuvens.com.br/id 
ensinavam. Historiadores de marketing costumam seguir a tradição dos economistas de separar a história da prática da história do pensamento e focar seu estudo em uma das duas. Desta forma, a pesquisa histórica do marketing divide-se em história do marketing e história do pensamento de marketing.

Já Yanaze (2007) conceitua o marketing como conhecimento do determinado produto ou serviço a ser lançado no mercado. Baseando na argumentação do autor Peter (2009) a definição do marketing aborda a forma da organização obter lucros no atendimento das características do seu grupo de consumidores, tendo finalidade de fixar atenção dos gestores aos seus clientes do que os próprios produtos que pretendem ofertar no mercado.

Na visão de Minadeo (2008) definir o marketing como uma orientação administrativa empresarial na determinação dos desejos, necessidades e valores do mercado, De acordo com Di Nallo (1999) o marketing encontra-se na linha divisória entre os modelos rígidos da economia e a interpretação do contexto social. Para Lambin (2000) o conceito de ação de marketing está dividido em duas abordagens e que podem ser avaliados em:

Quadro 02: Abordagens do Conceito e Ação de Marketing.

\begin{tabular}{|c|l|}
\hline $\begin{array}{c}\text { Marketing } \\
\text { Estratégico }\end{array}$ & $\begin{array}{l}\text { A abordagem de análise das necessidades do mercado, de identificação dos segmentos } \\
\text { desse mercado, da sua atratividade, do nível de competitividade e da escolha de uma } \\
\text { estratégia e de um posicionamento. }\end{array}$ \\
\hline $\begin{array}{c}\text { Marketing } \\
\text { Operacional }\end{array}$ & $\begin{array}{l}\text { A abordagem de ação operacional sobre o segmento alvo escolhido, definindo objetivos } \\
\text { e táticos, por meio de um plano de marketing, da definição das ações do marketing mix, } \\
\text { do estabelecimento do orçamento de marketing e da implantação e controle. }\end{array}$ \\
\hline
\end{tabular}
Fonte: Adaptado de Lambim (2000).

No entanto, o objetivo principal das funções de marketing é, desenvolver um amplo entendimento do ambiente de mercado para que possa garantir que a empresa esteja produzindo os produtos e serviços que o consumidor deseja. Assim, com um mix de produtos disponível, a função do marketing, passa a ser responsável por gerar a demanda necessária para esses produtos, por criar a preferência dos consumidores por meio de comunicação de massa ou pessoal, e pelo gerenciamento do canal de distribuição por onde os produtos estariam disponíveis para os consumidores (LAMBIM, 2000). 


\section{Planejamento de Marketing Estratégico}

Em pleno século XXI, onde a dinâmica da concorrência impõe com frequência novos desafios para as organizações, é necessário repensar a metodologia e a prática do planejamento de marketing estratégico. Nesta visão, o teórico Dias (2008) afirma que o primeiro desafio de uma organização prestes a ser lançada no mercado é definir seu cliente alvo, ou seja, segmentar o seu mercado. Mas, para segmentar o mercado é preciso um esforço para aumentar a precisão do marketing da empresa, como observar as características e comportamento do cliente. Dentre essas caraterísticas estão: Preferências, poder de compra, localização geográfica, atitudes de compra e hábitos de compra similares (KOTLER, 2000).

Kotler (2000) ainda ressalta em sua fala que desta forma, as empresas, podem melhorar e direcionar suas estratégias de marketing, principalmente em relação à definição de produtos, promoções, política de preços, e distribuição. Ou seja, em vez de tentarem concorrer em todos os mercados, devem identificar os segmentos que poderão atender melhor, criando uma imagem positiva junto ao comprador,

Neste contexto apresentado sobre a importância da segmentação de mercado o Planejamento Estratégico de Marketing passa ser a ferramenta fundamental na gestão empresarial, pois transforma as atividades da empresa em estratégias claras, servindo, ainda, para o alinhamento da visão dos gestores e direcionamento de recursos (DIAS, 2008).

Sendo assim, o papel do marketing estratégico passa a ser a visão macro da empresa e, justamente por isso, sua função é estratégica, vindo antes da produção e do tático da empresa. Em outras palavras, é responsável pelo planejamento geral de estratégias para toda a organização (ROCHA, 2015).

Sob o ponto de vista da gestão da empresa, é necessário que o gestor esteja atento as mudanças de comportamento dos seus clientes e desenvolva uma visão estratégica não apenas de vendas, mas de toda a estrutura organizacional (HOOLEY; PIERCY; NICOULAUD, 2011; HUGHES, 2005; KOTLER et al., 2008).

Para estes autores citados no parágrafo anterior, segmentar o mercado significa escolher um grupo de consumidores, com necessidades homogêneas, para o qual a empresa poderá fazer uma oferta mercadológica. O processo de segmentação requer que sejam identificados os 
fatores que afetam as decisões de compras dos clientes, cujos requisitos para a segmentação, possam ser identificável, mensurável, acessível, rentável e estável.

Já no ponto de vista do teórico Almeida (2010) o Planejamento Estratégico de Marketing, demanda que a organização faça uma análise do ambiente interno e externo, ou seja, identifique os seus pontos fortes e fracos. Neste sentido a empresa deve aprender a se concentrar nas necessidades dos clientes e explorar todos os caminhos que possam the proporcionar vantagem e diferencial sobre seus concorrentes. Esse planejamento assume a forma de um plano de marketing integrado de funções e recursos disponíveis.

Para isso Stevens et al. (2001) afirma que durante a condução da análise do planejamento de marketing da situação da organização, é formular um conjunto de objetivos e delinear estratégias como respostas da companhia para as oportunidades do mercado. Isto significa que antes de tomar decisões sobre produtos, deverá antecipadamente já ter sido analisado como este deve ser configurado para pôr em prática uma estratégia centrada na exploração de uma vantagem competitiva em um mercado-alvo específico.

Os autores Kotler e Armstrong (2003), afirmam que para o sucesso de um programa eficaz de marketing é necessário que todos os elementos do composto de marketing estejam reunidos e conectados um ao outro. A seguir a figura 02 demonstra o conjunto composto e táticas da empresa para criar um forte posicionamento nos mercados-alvo.

Figura 02: O Composto de Marketing.

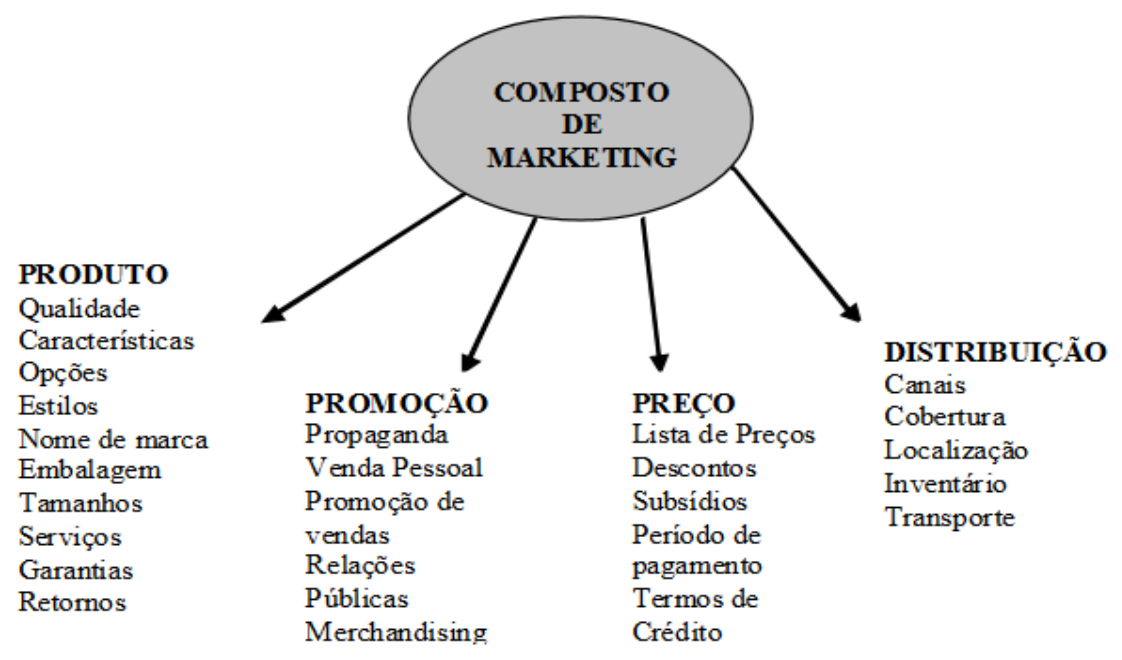

Fonte: Extraído Cobra (1992). 
A partir da imagem 01, pode-se observar que não pode se pensar em estratégias organizacionais isoladamente. $\mathrm{O}$ produto se constitui no principal elemento do composto mercadológico. A possível determinar o preço, a distribuição e a promoção. Desta forma, a partir do estudo deste elemento do composto, podemos desenvolver ações também para os demais. Este mesmo autor, afirma que manter clientes importantes não basta, é importante dar continuidade ao acompanhamento pós-vendas sobre a recomendação e desejos atribuídos do produto ou serviço adquirido.

\section{Comportamento do Consumidor}

Buscar compreender o comportamento da clientela sempre foi uma atividade desafiadora de qualquer profissional de marketing, tendo Merlo e Ceribelli (2013) ao argumentarem que quando é feito o estudo do comportamento do consumidor, busca-se investigar os motivos dos clientes em adquirir produtos e serviços, sobre fatores internos e externos influenciastes em suas decisões, sendo avaliados posteriormente ao uso e como fazem o descarte determinando a sua satisfação.

Samara e Morsch (2012) afirma que a complexidade atribuída ao ser humano é determinada em diversas áreas do conhecimento trazendo diversos fatores que ajudam na determinação do perfil dos consumidores em fazerem utilidade de produtos e serviços sobre diversos aspectos em deixarem motivados, já que o cliente é tesouro mais valioso de qualquer negócio tendo funcionalidade através da sua satisfação.

Portanto, observar e estudar o comportamento dos clientes é a essência funcional do trabalho do marketing onde pode cumprir com mais efetividade os determinados objetivos organizacionais, tendo desenvolvimento na produtividade em atendimento as demandas exigidas obtendo contribuição para o sucesso do negócio que inicia o trabalho da administração mercadológica com objetivo de ter o conhecimento aprofundado sobre o perfil dos clientes diante do mercado (SAMARA; MORSCH, 2012).

Sendo que cada comprador possui diversas características distintas ao que pretende obter, destacando Camargo (2013) em afirmar que não é fácil conseguir entender o comportamento do consumidor onde por outro lado o marketing busca compreender as ações 
motivadas compostas no seu determinado comportamento, podendo-se entender que os consumidores fazem a utilidade dos produtos ou serviços sobre diversas formas variadas.

Já que cada pessoa possui a liberdade de determinar sua personalidade consumidora, citando Solomon (2016) em afirmar que a forma vista pelas pessoas em consumir determinados produtos e serviços é chamado cultura, onde obtém muitos efeitos no comportamento do consumidor com muita eficiência sendo moderadamente difícil em compreender sua importância. Tendo relação com Merlo e Ceribelli (2013) ao abordarem que o conhecimento do comportamento do consumidor é feito por um dos processos de compreensão dos gestores de marketing onde a cultura é um dos fatores importantes, sobre a forma de convivência aprendida entre os membros da sociedade, tendo o conhecimento compartilhado em manter a estabilidade e o equilíbrio sobre relações pessoais com necessidades para inovação organizacional.

Estes autores também destacam outros fatores influenciastes sobre o comportamento do consumidor como o grupo social ligado a cultura no caso do conhecimento em determinação do comportamento padronizado sendo compartilhado entre dois ou mais indivíduos podendo ter relações pessoais muitas e poucas frequentes. Assim como a classe social em determinação do prestígio adquirido em devida ocupação no mercado de trabalho com o salário de nível atribuído, onde quanto maior o prestígio da ocupação mercadológica, maior será a classe social atribuída com renda elevada, caso contrário obterá o prestígio inferior da classe posicionada na sociedade.

Assim obtém-se sentido que o estudo do comportamento dos clientes é feito através da compreensão e análise desses fatores sociais importantes pelos gestores de marketing onde fornecem estratégias na tomadas de decisões tendo resultados competentes, Segundo Hawkins, Mothersbaugh e Best (2007) as formas e táticas usadas são relacionadas explicitamente ao comportamento do consumidor onde há maior probabilidade de encontrar a forma certa na tomada de decisões gerando vantagens competitivas, assim como ter a redução da probabilidade de erros prejudiciais ao tomar decisões inadequadas ao negócio.

1128 Id on Line Rev. Mult. Psic. V.12, N. 42, p. 1119-1142, 2018 - ISSN 1981-1179 Edição eletrônica em http://idonline.emnuvens.com.br/id 


\section{Fidelização de Cliente}

Face as constantes mudanças no cenário mundial, o mercado torna-se cada vez mais disputado, com produtos bastante semelhantes e clientes que buscam por valores agregados e inovação. Definido o termo cliente Las Casas (2013, p. 181), afirma que "Cliente é uma pessoa ou organização que tem um papel na consumação de uma transação com o vendedor ou entidade", ou seja, isso significa que o cliente é visto como item fundamental e mais importante para o resultado positivo de uma empresa.

Corroborando com Las Casas (2013) os autores Nickels e Wood (1999, p. 06) a firma que o cliente é "um indivíduo ou organização que compra ou troca alguma coisa de valor pelos produtos vendidos". É necessário que as empresas estabeleçam um relacionamento duradouro com seus clientes, capaz de conhecer as suas características, gostos e desejos, definindo assim a fidelização de clientes.

De acordo Santos (2008) a fidelização de clientes é medir, gerenciar e criar valor. É tornar a fidelização de clientes parte integrante da missão da empresa, integrando sistemas de informação, criando valor superior, ou seja, transformando clientes satisfeitos em clientes fiéis. Portanto é importante compreender que o atendimento prestado com qualidade não se resume apenas ao tratamento ou cortesia, mais do que isso, significa acrescentar benefícios a produtos e serviços, com o objetivo de superar as expectativas do consumidor.

Os teóricos Kotler e Keller (2006, p. 144) ressaltam que toda empresa deve medir constantemente o grau de satisfação de seus clientes, a fim de mantê-los por mais tempo dentro de sua empresa. Um cliente satisfeito compra mais, e traz consigo outros clientes para dentro da empresa. Corroborando com Kotler e Keller (2006) os autores Kotler e Armstrong (2003) afirmam que existe um diferencial entre a satisfação dos clientes, os clientes muito satisfeitos produzem diversos benefícios para a empresa, e que clientes satisfeitos são menos sensíveis aos preços, falam bem da empresa e de seus produtos a outras pessoas e permanecem fiéis por um período mais longo.

No entanto através desta percepção dos autores, percebe-se como é importante ouvir o cliente, atender bem e encanta-los através de seus produtos e serviços de qualidade. De acordo com Majeau (2010), quando a empresa trabalha fortemente a fidelização de seus clientes, através de seus produtos e serviços prestados com qualidade os custos com marketing da própria 
marca tornam se ínfimos. A fidelidade do cliente oferece a empresa defesas contra a concorrência por preço. Para os teóricos Slack, Chambers e Johnston (2002), a qualidade no atendimento deve ir do início ao fim, com relevância ao serviço ou produtos, desempenhando de forma coerente, visando a satisfação do cliente. Para que ele possa voltar a comprar novamente e possa indicar para outras pessoas, é preciso que estejam

\section{Metodologia}

Esta pesquisa é aplicada quanto à sua natureza descritiva, exploratória e de cunho quantitativo com fundamentação bibliográfica Segundo Gil (2010) a vantagem principal obtida da pesquisa bibliográfica é permitir ao investigador descobrir uma série de fenômenos muito mais do que se pode realizar a pesquisa. Tendo a pesquisa de campo pelo motivo de dados serem coletados no ambiente da organização, Gil (2010) também afirma que os ambientes que são pesquisados têm muitas diversificações assim como os métodos e coletas para a interpretação dos dados obtidos.

Sendo também descritiva em função de distinguir as características do grupo onde deseja conhecer, ainda na visão de Gil (2010) essa pesquisa vai além do conhecimento das relações sobre variedades próprias determinando sua naturalidade. E exploratória com a finalidade de se aprofundar em ter novos resultados de estudos no assunto a ser pesquisado, de acordo com Barquette (2007), o objetivo dessa pesquisa é buscar entender os acontecimentos do problema procurando desenvolvimento.

A abordagem metodológica desta pesquisa é análise quantitativa que consiste em definir um problema, desenvolver um modelo, obter dados de entrada, determinar uma solução, testar a solução, analisar os resultados e implementar os resultados KLEIN et al. (2015). A amostragem foi realizada por conveniência. Os sujeitos da pesquisa foram 150 (cento e cinquenta) discentes de uma IES particular na cidade de Juazeiro do Norte-CE que consomem alimentos em cantinas, e em comércios ambulantes que ficam localizados próximos a IES particular. O instrumento de pesquisa foi através de um questionário contendo 12 perguntas estruturadas entre abertas e fechadas para obtenção de respostas. Após a coleta os dados, as informações foram tratadas e tabulados através de planilhas do software Excel, onde 
posteriormente foram gerados gráficos para uma melhor visualização e compreensão dos resultados obtidos com a fundamentação teórica apresentada neste estudo.

\section{Análise e Discussão dos Resultados}

A coleta dos dados desta pesquisa foi realizada nos meses de setembro e outubro de 2018, através de aplicação de questionários estruturados com 12 (doze) perguntas entre abertas e fechadas a uma amostra de 151 (cento e cinquenta e um) discentes de uma IES particular na cidade de Juazeiro do Norte - CE. A pesquisa utilizou como forma de amostragem a conveniência dos participantes.

Quadro 01: Cruzamento de Gênero e Faixa Etária.

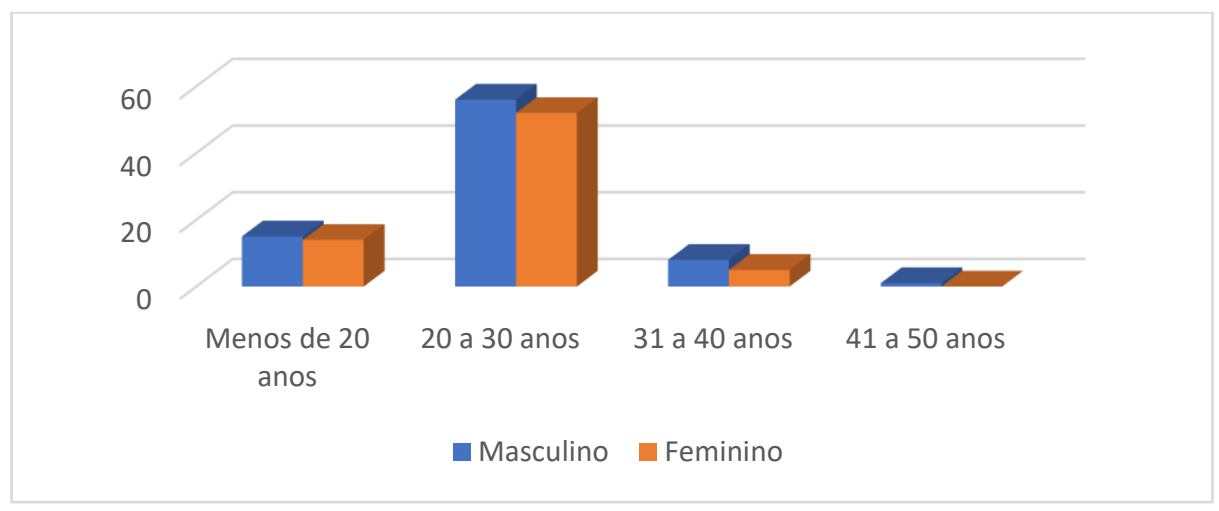

Fonte: Dados da Pesquisa 2018.

Os dados do gráfico 01 são o cruzamento do gênero e faixa etária dos participantes da pesquisa. Os dados revelam que 53\% dos entrevistados tem predominância do gênero masculino quanto $47 \%$ ao gênero feminino. Observa-se também que em relação a faixa etária a maior predominância está apartir dos 20 à 30 anos. A faixa etária é um dos fatores a ser analisados na formação do comportamento do consumidor. Para os autores Hooley; Piercy; Nicoulaud (2011); Hughes, (2005); Kotler et al., (2008), segmentar o mercado significa escolher um grupo de consumidores, com necessidades homogêneas, para o qual a empresa poderá fazer uma oferta mercadológica. O processo de segmentação requer que sejam 
identificados os fatores que afetam as decisões de compras dos consumidores, com requisitos para a segmentação, sendo identificável, mensurável, acessível, rentável e estável.

Quadro 02: Cruzamento de Curso de Formação e Faixa Etária.

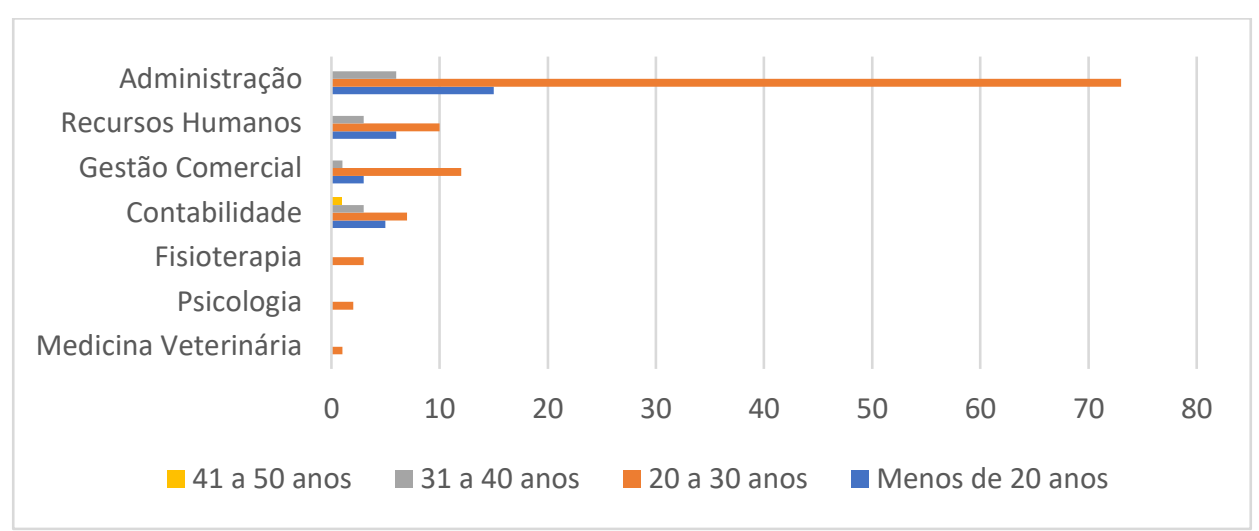

Fonte: Dados da Pesquisa 2018.

No gráfico 02 percebe-se que a maior proporção dos participantes da pesquisa pertence ao curso de Administração e estes estão na faixa etária dos 20 a 30 anos. Para planejar um empreendimento, é necessário segmentar o mercado que o mesmo pretende atuar, identificando os fatores de influência que envolve o comportamento do consumidor. Entre esses fatores podem-se destacar os culturais, sociais, pessoais e psicológicos. Diante deste contexto, o resultado desses índices pode ser utilizado na tomada de decisão estratégica.

Gráfico 03: Quanto à Frequência de Visitas aos Empreendedores Ambulantes Alimentícios.

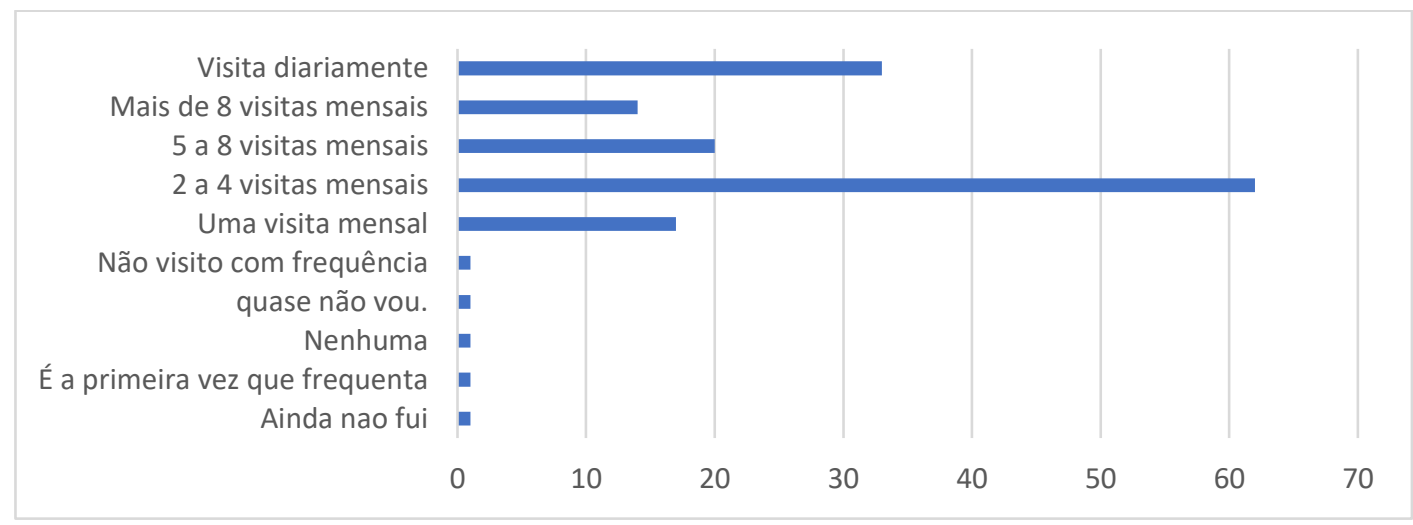

Fonte: Dados da Pesquisa 2018. 
Uma das questões a reconhecer sobre os consumidores é a frequência de compra dos clientes. Os teóricos Kotler e Keller (2006, p. 144) ressaltam que toda empresa deve medir constantemente o grau de satisfação de seus clientes, a fim de mantê-los por mais tempo dentro de sua empresa. Um cliente satisfeito compra mais, e traz consigo outros clientes para dentro da empresa.

Pensando nessa problemática, o gráfico 03 demonstra que entre as faixas pesquisadas a maior proporção entre os participantes concentram-se, nos que frequentam de 02 (duas) à 04 (quatro) visitas por mês e a segunda maior proporção são os que frequentam diariamente om empreendedores ambulantes alimentícios. No entanto, no ponto de vista organizacional, a competitividade do mercado empresarial, torna-se necessário a adoção de técnicas que concedam às empresas diferenciais estratégicos, a fim de manter os clientes já existentes e garantir-lhes satisfação para com o produto e ainda conquistar futuros consumidores.

Gráfico 04: Atendimento Ofertado pelos Empreendedores Ambulantes Alimentícios.

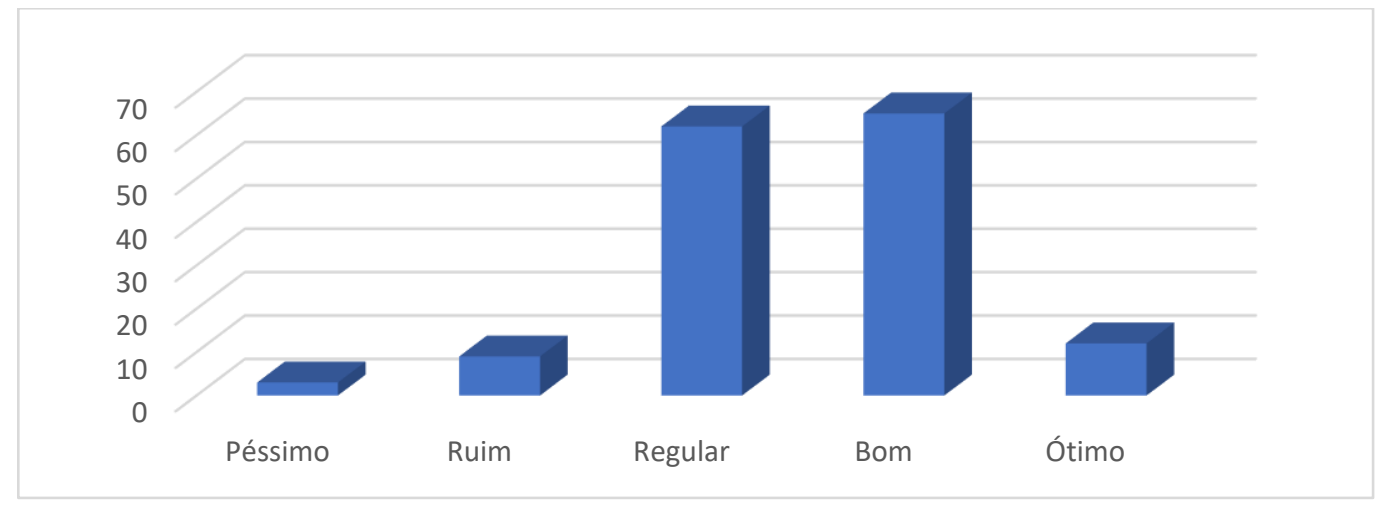

Fonte: Dados da Pesquisa 2018

Antes de discutir a análise dos resultados do gráfico 04 é importante destacar Kotler que os teóricos Keller (2006) afirmam que toda empresa deve medir a satisfação com regularidade, porque a chave para reter clientes está em satisfaze-los. Em geral, um cliente altamente satisfeito permanece fiel por mais tempo, compra mais à medida que a empresa lança produtos ou aperfeiçoa aqueles existentes, fala bem da empresa e de seus produtos, dá menos atenção a marcas e propaganda concorrentes e é menos sensível a preço. 
Portanto, foi observado no gráfico 04 que o atendimento ofertado ao cliente pelos empreendedores ambulantes alimentícios carece de uma gestão estratégica de marketing voltada para a qualidade do atendimento. Pois percebe-se que a variável de "ótimo atendimento" deixa muito a desejar. Segundo Slack, Chambers e Johnston (2002), a qualidade no atendimento é de suma relevância. Seja serviços ou produtos, todos se desempenhados de forma coerente, poderão trazer a satisfação ao cliente e fazê-lo ele voltar a comprar novamente.

Gráfico 05: Mix de Produtos Oferecidos pelos Empreendedores Ambulantes.

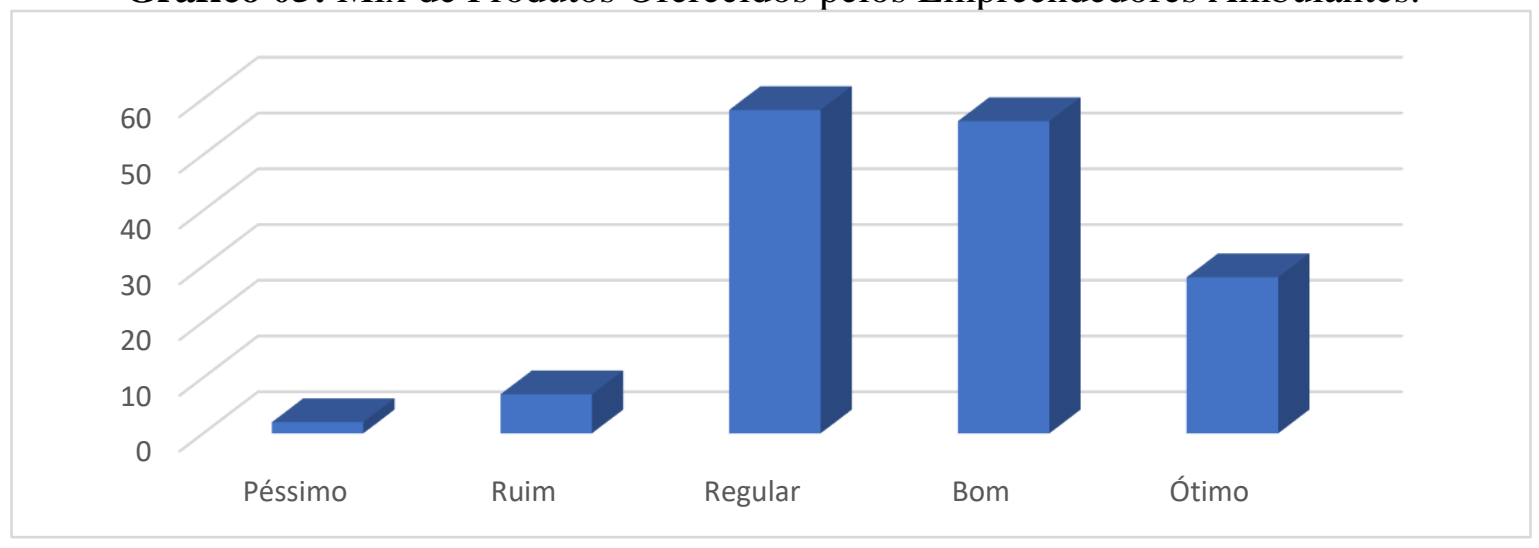

Fonte: Dados da Pesquisa 2018.

Os resultados do gráfico 05 demonstram que existe uma insuficiência no mix de produtos ofertados pelos empreendedores ambulantes alimentícios. Tendo em vista que entre os respondentes da pesquisa, a maioria afirmou que a variedade de produtos está entre "Bom" e "Regular", tendo uma pequena amostra da vaiável "ótimo".

É importante destacar que o mix de produtos é um fator determinante para o sucesso de uma empresa, independentemente do segmento de atuação. O mix de varejo aborda todas as variáveis que podem influenciar no comportamento de compra do consumidor. Através dele, a empresa aperfeiçoa o relacionamento com clientes, aumenta o faturamento e evita que consumidor tenha que recorrer à concorrência, por não ter as suas demandas devidamente atendidas. 
Gráfico 06: Comodidade para Efetuar os seus Lanches.

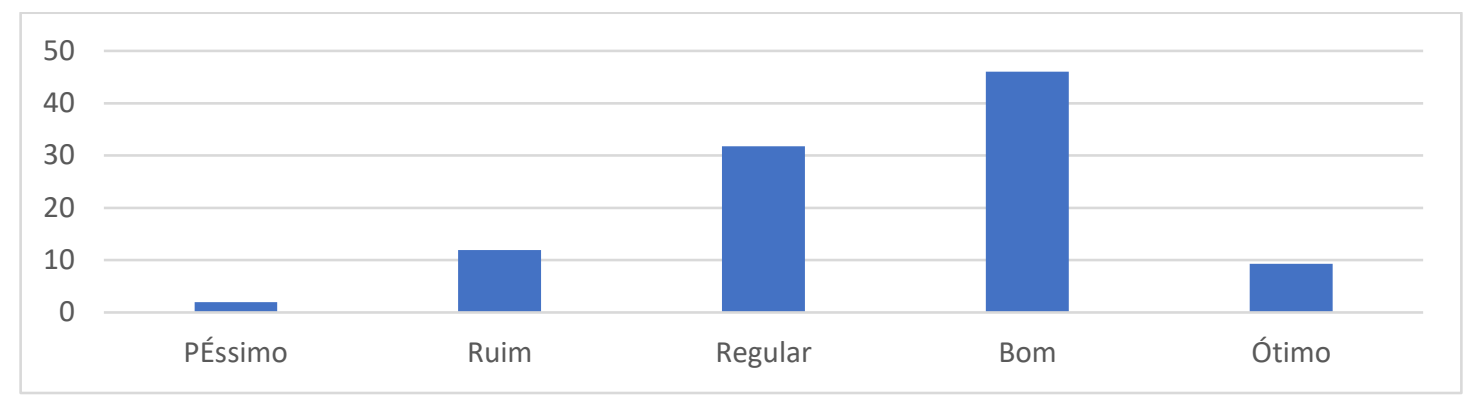

Fonte: Dados da Pesquisa 2018.

Em um mercado cada vez mais competitivo, é imprescindível que as organizações se preocupem em fidelizar seus clientes. As comodidades e avanços do comércio criaram consumidores mais exigentes, que não se satisfazem mais apenas em um produto de qualidade: esperam também um atendimento atencioso, pós-venda de qualidade e uma prestação de serviços eficiente. Diante desta perspectiva, o gráfico 06 revela que na maioridade dos participantes avaliaram a Comodidade para efetuar os seus lanches como "Bom" e "Regular", a variável "ótimo" teve uma pequena porcentagem.

Gráfico 07: Comparativo de Preços - Ambulantes X Cantinas.

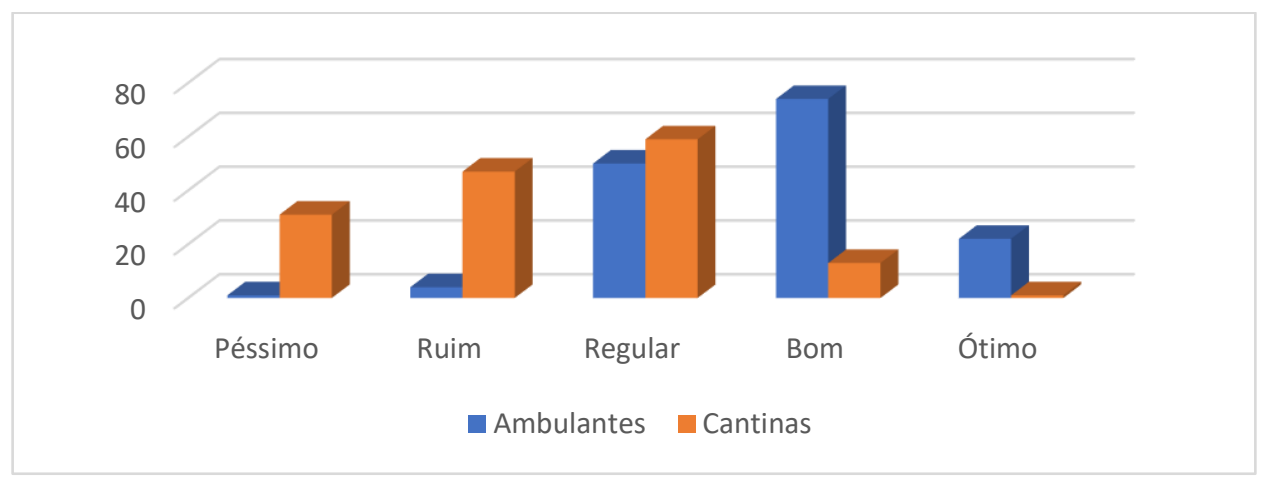

Fonte: Dados da Pesquisa 2018

Os dados do gráfico 07 revelam que em sua maioridade os participantes afirmaram que preços praticados pelos empreendedores ambulantes alimentícios são mais acessíveis a suas condições financeiras. Percebe-se que a avaliação sobre os preços praticados pelas cantinas foi avaliada de forma negativa pelos participantes da pesquisa. 
Gráfico 08: Comparativo do Marketing de Relacionamento - Ambulante x Cantinas.

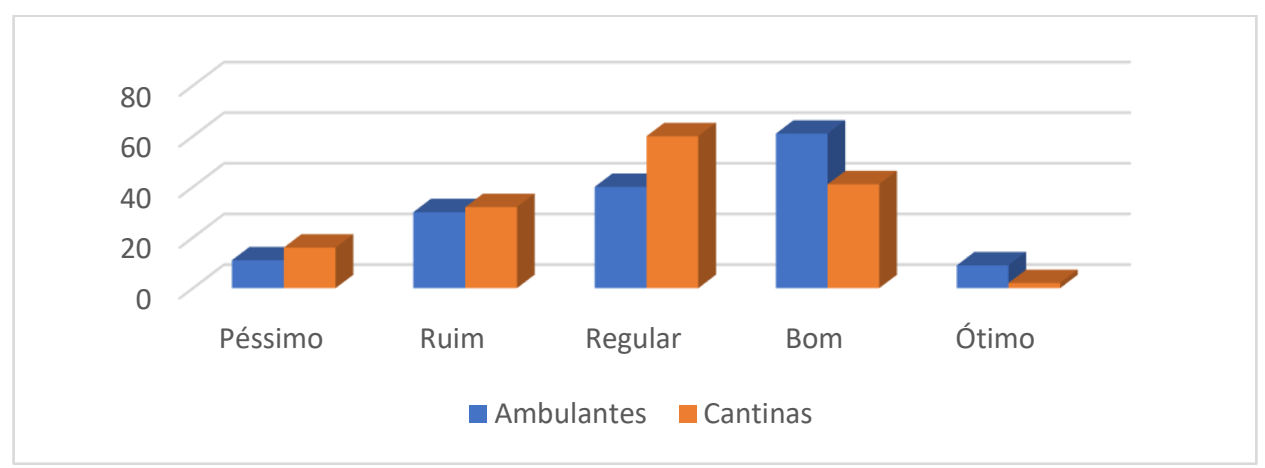

Fonte: Dados da Pesquisa 2018.

Em relação ao gráfico 08 sobre a comparação do marketing de relacionamento entre cantinas e ambulantes a maioria absoluta dos participantes afirmou reconhecer que os empreendedores ambulantes alimentícios utilizam uma boa estratégica de relacionamento ao cliente comparado a estratégias das cantinas da IES. Percebe-se as estratégias utilizadas pelas cantinas da IES foram avaliadas como apenas como "regular".

Quadro 09: Grau de Satisfação com os Produtos e Serviços Oferecidos pelos Ambulantes

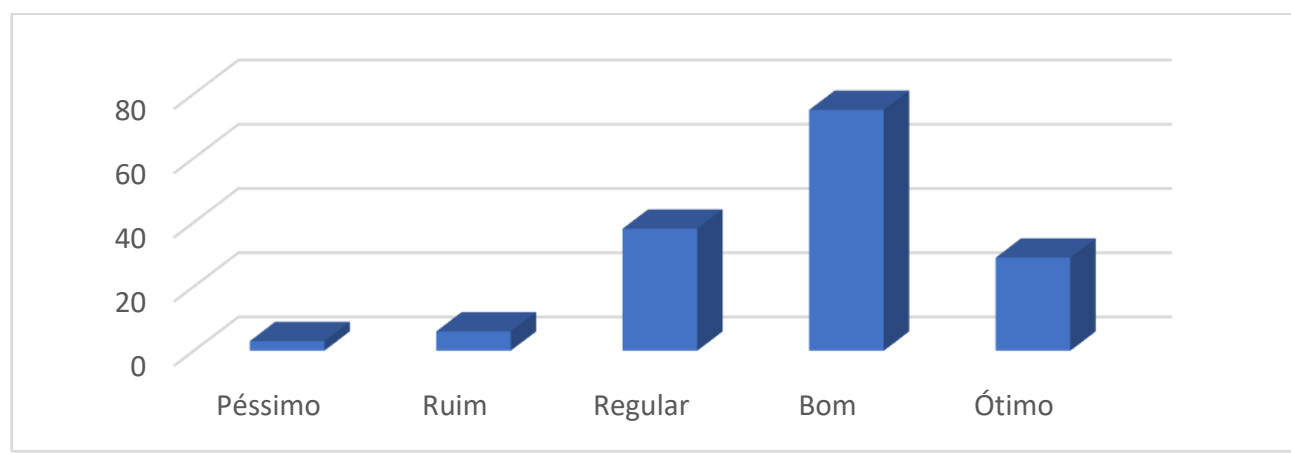

Fonte: Dados da Pesquisa 2018

O gráfico 09 mostra o grau de satisfação dos participantes sobre produtos e serviços ofertados pelos empreendedores ambulantes alimentícios, tendo mais uma vez a predominância da variável "bom". Os clientes precisam se sentir satisfeito, e para que isso aconteça as organizações precisam ter qualidade no atendimento. Dessa forma o bom atendimento se torna a peça chave para a empresa obter vantagem no mercado competitivo. 
Kotler e Armstrong (2003) afirmam que existe um diferencial entre a satisfação dos clientes, os clientes muito satisfeitos produzem diversos benefícios para a empresa, e que clientes satisfeitos são menos sensíveis aos preços, falam bem da empresa e de seus produtos a outras pessoas e permanecem fiéis por um período mais longo.

Quadro 10: Ambiente que os Empreenderes Ambulantes Alimentícios estão Localizados.

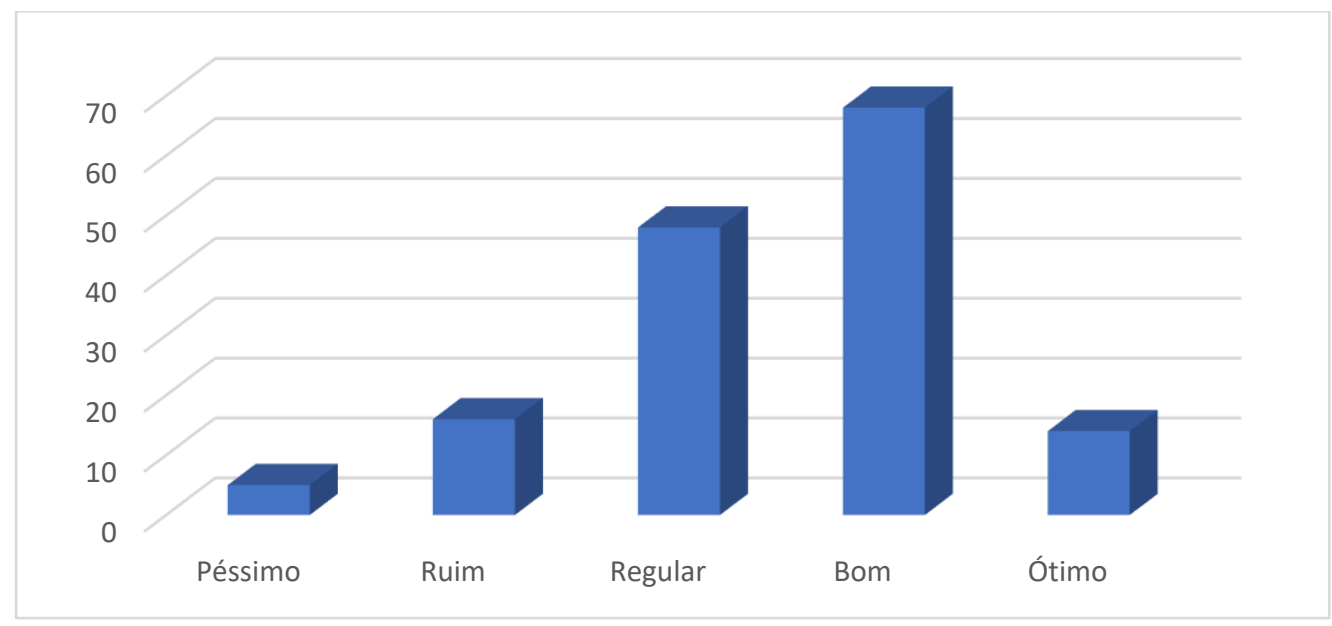

Fonte: Dados da Pesquisa 2018.

Percebe-se no gráfico 10, que apesar dos empreendedores ambulantes alimentícios estarem localizados em meio de ruas, lugares desprovidos de segurança, higiene, iluminação e infraestrutura adequada para um negócio a maioridade dos participantes avaliaram a localização como "Bom".

Por fim, foi inquerido aos participantes da pesquisa sobre quais os serviços ofertados pelos ambulantes são considerados como fator diferencial e competitivo frente às cantinas e entre as respostas foram citados por supremacia os fatores de: Atendimento, Preço acessível, Preço acessível, Mix de produtos, Qualidade do produto e Cortesia de sucos. A última pergunta do questionário é sobre os fatores que levam os participantes da pesquisa optar pelos alimentos ofertados pelos empreendedores ambulantes. Entre os respondentes a apontou o preço, a qualidade do produto, o atendimento e falta de opção. 


\section{Considerações Finais}

A pesquisa buscou identificar os fatores que levam os discentes de uma IES particular optar por produtos alimentícios comercializados por empreendedores ambulantes na cidade de Juazeiro do Norte-CE. Após a conclusão deste estudo, conclui-se que os objetivos propostos foram alcançados e que as hipóteses investigadas foram confirmadas positivamente pelo pesquisador.

$\mathrm{Na}$ análise da pesquisa com os discentes da IES particular na cidade de Juazeiro do Norte-CE constatou-se que, a grande maioria dos entrevistados pertence ao curso de Administração, são do gênero masculino e possuem de 20 à 30 anos. Merlo e Ceribelli (2013) afirma que o conhecimento do comportamento do consumidor é feito por um dos processos de compreensão dos gestores de marketing onde a cultura é um dos fatores importantes na característica do cliente.

Perante essa problemática, a pesquisa revelou que no ponto de vista dos participantes da pesquisa, os empreendedores de ambulantes alimentícios utilizam - se de estratégias competitivas em relação as cantinas da IES particular. Observa-se que os fatores que levam a escolher os produtos ofertados pelos empreendedores ambulantes estão relacionados ao bom atendimento, o mix de produtos, a comodidade para efetuar seus lanches, o preço, ambiente, o relacionamento com o cliente, o grau de satisfação com os produtos e serviços ofertados.

Diante dos procedimentos teóricos-metodológicos utilizados no presente artigo, conclui-se que faz necessário o avanço de novos estudos e pesquisas sobre o planejamento de marketing estratégico competitivo dentro das organizações, sejam elas de pequeno porte ou não.

\section{Referências}

ALMEIDA, Martinho Isnard de. Manual de planejamento estratégico: Desenvolvimento de um plano estratégico com a utilização de planilhas Excel. 3 ed. Atlas, 2010.

AGUILERA, José Carlos. Gestão Estratégica de mudanças corporativas. São Paulo. Saraiva. 2009.

ALVAREZ, Francisco J. S. M. Gestão Estratégica de Clientes. São Paulo: Saraiva, 2015.

\section{Id on Line Rev. Mult. Psic. V.12, N. 42, p. 1119-1142, 2018 - ISSN 1981-1179} Edição eletrônica em http://idonline.emnuvens.com.br/id 
BARQUETTE, Stael. Pesquisa de Marketing. Saraiva, 07/2007. [Minha Biblioteca].

CAMARGO, Pedro Celso de. Neuromarketing: a nova pesquisa de comportamento do consumidor. Atlas, 02/2013. [Minha Biblioteca].

CASAS, Las, Alexandre Luzzi. Administração de Marketing: Conceitos, Planejamento e Aplicações à Realidade Brasileira. Atlas, 2006.

CHAUVEL, M. A. The History of Marketing Thought and "The GreatTransformation" of Polanyi: How To Conciliate Social and Economic Interests. In: BALAS CONFERENCE, 2001. San Diego. Anais... San Diego, 2001.

COBRA, Marcos. Administração de marketing. 2. ed. São Paulo: Atlas, 1992.

CORAL, Eliza. Modelo de planejamento estratégico para a sustentabilidade empresarial. 2002, Disponível em: < https: // repositorio.ufsc.br/bitstream/handle /123456789/82705/189235.pdf? sequence=1\&isAllowed=y > Acesso em: 31 mar. 2018.

DIAS, Reinaldo. Sociologia das organizações. Atlas, 01/2008. [Minha Biblioteca].Alvarez,

DI NALLO, E. Meeting points: soluções de marketing para uma sociedade complexa. São Paulo: Cobra, 1999.

FARRIS, Paul W, BENDLE, Neil T., PFEIFER, Phillip E., REIBSTEIN, David J. Métricas de Marketing. 2 2adição. Bookman, 2013.

GIL, Antônio Carlos. Como elaborar projetos de pesquisa. 5 ed. Atlas, 2010.

GIOVANINI, Fabrizio. Organização Eficaz. São Paulo. Nobel. 2004.

HARTLINE. Michael D, FERREL. O. C. Estratégia de Marketing. $4^{\mathrm{a}}$ ed. Norte Americana: Cengage Learning, 2010.

HAWKINS. Del I, MOTHERSBAUGH. David L, BEST. Roger J. Comportamento do consumidor: construindo a estratégia de marketing, $10^{\mathrm{a}}$ ed. Rio de Janeiro: Campus, 2007.

HOOLEY, G. J.; PIERCY, N. F.; NICOULAUD, B. Marketing Strategy and Competitive Positioning 4th Edition. [s.l.] Pearson/Prentice Hall, 2011.

HUGHES, A. M. Strategic database marketing: The Masterplan for Starting and Managing a Profitable, Customer-Based Marketing Program. New York: McGraw-Hill, 2005.

JONES, B.; SHAW, E. History of Marketing Thought. In:BARTONWEITZ; ROBINWENSLEY (Ed.). Handbook of Marketing. London: Sage. p. 39-65, 2002.

KLEIN, Amarolinda Zanela, SILVA, Lisiane Vasconcellos da, MACHADO, Lisiane, AZEVEDO, Debora. Metodologia de Pesquisa em Administração: Uma Abordagem Prática. Atlas, 01/2015. [Minha Biblioteca]. 
KOTLER, Philip e KELLER, Kevin Lane. Administração de Marketing. 12. Ed. São Paulo: Pearson Prentice Hall, 2006.

KOTLER, Philip e ARMSTRONG, Gary. Princípios de Marketing. 9. ed. São Paulo: Prentice Hall, 2003.

KOTLER, Philip. Administração de Marketing: a edição do novo milênio. 10.ed. São Paulo: Prentice Hall, 2000.

LAMBIN, J. J. Marketing estratégico. 4. ed. Lisboa: McGraw Hill, 2000.

MAJEAU, Pedro Mizcci. Fidelização de Clientes. 2010. Disponível em <http://www.negocios-devalor.com/fidelizacao_de_clientes.asp >. Acesso em 13 de agosto de 2018.

MERLO, Edgard Monforte, CERIBELI, Harrison B. Comportamento do Consumidor. LTC, 11/2013. [Minha Biblioteca].

MINADEO, Roberto. Gestão de marketing: fundamentos e aplicações. Atlas, 10/2008. [Minha Biblioteca].

MOTTA, F.C.P. A questão da formação do administrador. RAE - Revista de Administração de Empresas, FGV, Rio de Janeiro, v. 23, n. 4, out./dez. 1983.

NEVES, Marcos Fava. Planejamento e gestão estratégica de marketing. Atlas, 09/2005. [Minha Biblioteca].

NICKELS, William G.; WOOD, Marian Burk. Marketing, relacionamentos, qualidade e valor. Rio de Janeiro: LTC - Livros Técnicos e Científicos, 1999

OLIVEIRA. Djalma de Pinho Rebouças de. Estratégia empresarial e vantagem competitiva: como estabelecer, implementar e avaliar. $6^{a}$ ed. São Paulo: Atlas, 2009.

PETER, J. Paul. Introdução ao Marketing - Criando Valor Para os Clientes, $1^{\text {a }}$ Edição. Saraiva, 06/2009. [Minha Biblioteca].

READE, Dennis V., Marcos Rocha, Sérgio Luis Ignácio Oliveira, Andréa Chernioglo. Marketing estratégico. Saraiva, 03/2016. [Minha Biblioteca].

ROCHA, Angela da, Ferreira, Jorge Brantes, Silva, Jorge da. Administração de marketing: conceitos, estratégias, aplicações. Atlas, 02/2013. [Minha Biblioteca].

ROCHA, Marcos. Marketing estratégico.São Paulo: Saraiva, 2015.

SAMARA. Beatriz Santos, MORSCH. Marco Aurélio. Comportamento do consumidor: conceitos e casos, $1^{a}$ ed. São Paulo: Prentice Hall, 2005.

SANTOS, D. Fidelização de Clientes. 2008. Disponível em internet: http://www.administradores.com.br/artigos/marketing/fidelizacao-de-clientes/20882/. Acesso em: 13 ago. 2018. 
SLACK N., CHAMBERS S.; JOHNSTON R. Administração da Produção. Tradução de M. T. C. de oliveira, F.ALHER e H.L. Corrêa.2. ed. São Paulo: Atlas, 2002.

STEVENS, R.; LOUDON, D.; WRENN, B.; WRENN, W. Planejamento de marketing. São Paulo: Makron Books, 2000.

SIMÕES, Roberto. Iniciação ao marketing. São Paulo: Atlas, 1980.

SOLOMON, Michael R. O Comportamento do Consumidor, 11th edição. Bookman, 01/2016. [Minha Biblioteca].

YANAZE, Mitsuru Higuchi. Gestão de marketing e comunicação: avançados e aplicações, $2^{a}$ edição. Saraiva, 04/2007. [Minha Biblioteca].

ZENARO, Marcelo, PEREIRA, Maurício Fernandes . Marketing estratégico para organizações e empreendedores: guia prático e ações passo a passo. Atlas, 08/2013. [Minha Biblioteca].

\section{Apêndice}

\section{Questionário}

\section{Gênero}

( ) Masculino ( ) Feminino

\section{Faixa etária}
( ) menos de 20 ano
( ) 20 a 30 anos
( ) 31 a 40 ano
( ) 41 a 50 anos
( ) 51 a 60 anos
( ) mais de 60 anos

\section{Curso de formação}

( ) Administração ( ) Gestão Comercial ( ) Recursos Humanos ( ) Fisioterapia
( ) Psicologia
( ) Contabilidade
( ) Odontologia ( ) Medicina Veterinária

1 - Quanto à frequência de visitas ao comércio
( ) Uma visita mensal
( ) de 2 a 4 visitas mensais
( ) 5 a 8 visitas mensais
( ) mais de 8 visitas mensais
( ) Visita diariamente
( ) É a primeira vez que frequenta.

Outro.

2 - Quanto ao atendimento ofertado pelos ambulantes no setor alimentício

( ) Péssimo ( ) Ruim ( ) Regular ( ) Bom ( ) Ótimo

3 - Quanto a variedade de produtos oferecidos pelos ambulantes no setor alimentício

( ) Péssimo ( ) Ruim ( ) Regular ( ) Bom ( ) Ótimo

4 - Quanto à localização do comércio ambulante em relação a sua comodidade para efetuar seus lanches. 
( ) Péssimo ( ) Ruim ( ) Regular ( ) Bom ( ) Ótimo

5 - Quanto aos preços praticados pelos ambulantes.

( ) Péssimo ( ) Ruim ( ) Regular ( ) Bom ( ) Ótimo

6 - Quanto aos preços praticados pelas cantinas

( ) Péssimo ( ) Ruim ( ) Regular ( ) Bom ( ) Ótimo

7 - Quanto ao marketing de relacionamento praticado pelos ambulantes em relação ao cliente.

( ) Péssimo ( ) Ruim ( ) Regular ( ) Bom ( ) Ótimo

8 - Quanto ao marketing de relacionamento praticado pelas cantinas em relação ao cliente.

( ) Péssimo ( ) Ruim ( ) Regular ( ) Bom ( ) Ótimo

9 - De modo geral, qual o seu grau de satisfação com os produtos e serviços Oferecidos pelos ambulantes.

( ) Péssimo ( ) Ruim ( ) Regular ( ) Bom ( ) Ótimo

10 - Quais os serviços ofertados pelos ambulantes no setor alimentício você considera como fator diferencial e competitivo.

$11^{\circ} \mathrm{O}$ que leva você escolher os alimentos ofertados pelos ambulantes no setor de alimentos próximo desta IES?

$12^{\circ}$ você acredita que os ambulantes no setor de alimentício utilizam-se estratégias de marketing para atrair e reter clientes?

( ) Sim ( ) Não

Justifique sua escolha.

Como citar este artigo (Formato ABNT):

SANTOS, Samuel Pinheiro dos; LIMA, Márcia Maria Leite. Marketing Estratégico como Fator Competitivo nas Organizações de Pequeno Porte. Id on Line Rev.Mult. Psic., 2018, vol.12, n.42, p. 1119-1142. ISSN: 1981-1179.

Recebido: 28/06/2018;

Aceito: $30 / 10 / 2018$ 